\title{
An Empirical Model for the Design of Batteries
}

\section{with High Energy Density}

\author{
Yingqiang Wu, ${ }^{\xi \dagger}$ Leqiong Xie, ${ }^{\perp \dagger}$ Hai Ming, ${ }^{\& \dagger}$ Yingjun Guo, ${ }^{£}$ Jang-Yeon Hwang, ${ }^{\zeta}$ Wenxi Wang,,${ }^{\dagger}$ \\ Xiangming He, ${ }^{\perp}$ Limin Wang, ${ }^{\S}$ Husam N. Alshareef, ${ }^{* *}$ Yang-Kook Sun ${ }^{\zeta *}$ and Jun Ming ${ }^{\S *}$
}

$\S$ State Key Laboratory of Rare Earth Resource Utilization, Changchun Institute of Applied Chemistry, Chinese Academy of Sciences, Changchun 130022, P. R. China.

${ }^{\perp}$ Institute of Nuclear and New Energy Technology, Tsinghua University, Beijing 100084, P.

R. China.

\& Research Institute of Chemical Defense, Beijing 100191, P. R. China.

${ }^{£}$ Huzhou Kunlun Power Battery Materials Co., LTD. Huzhou, 313000, P. R. China.

$\zeta$ Department of Energy Engineering, Hanyang University, Seoul 133-791, Republic of Korea.

\$Physical Science and Engineering Division (PSE), King Abdullah University of Science and Technology (KAUST), Thuwal, 23955-6900, Saudi Arabia.

$\dagger$ These authors contribute equally

* To whom correspondence should be addressed: husam.alshareef@kaust.edu.sa; yksun@hanyang.ac.kr; jun.ming@,ciac.ac.cn. 


\begin{abstract}
The development of rechargeable batteries beyond $300 \mathrm{Wh} \mathrm{kg}^{-1}$ for electric vehicles remains challenging, where low capacity electrode materials (especially graphite anode, 372 $\mathrm{Ah} \mathrm{kg}^{-1}$ ) remain as the major bottleneck. Although many high capacity alternatives (e.g., Sibased alloys, metal oxides, or Li-based anode) are being widely explored, the energy density achieved has not exceeded $300 \mathrm{Wh} \mathrm{kg}^{-1}$. Herein, we present a new empirical model that considers multiple design parameters, besides electrode capacities, including areal loading density, voltage difference, initial capacity balance between anode and cathode, and initial Coulombic efficiency to estimate the achievable energy density. This approach is used to predict battery design that can achieve energy density above $300 \mathrm{Wh} \mathrm{kg}^{-1}$. The model reveals that the lithium storage capacity of electrode materials is only one of several important factors affecting the ultimate battery energy density. Our model provides a new way to review the current battery systems beyond the prism of electrode capacity and also presents a straightforward guideline to design batteries with higher energy densities.
\end{abstract}

\title{
TOC
}

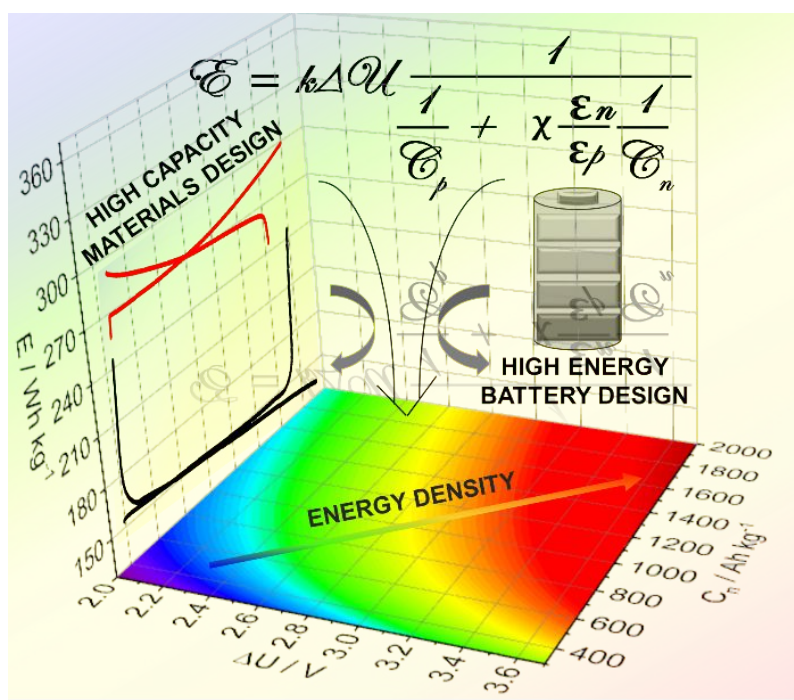


Rechargeable lithium-ion batteries (LIBs) have dominated the energy storage market from portable electronic devices, electric vehicles (EVs), and smart grids since their commercialization in $1991 .^{1-3}$ However, the battery energy density obtained so far does not satisfy the increasing energy storage demands, especially for long-range EV range beyond 500 km. ${ }^{4-6}$ Although different types of batteries (e.g. high voltage LIBs, Li-S battery, and Li-metal battery) have been extensively studied, ${ }^{7-11}$ achieving energy density beyond $300 \mathrm{Wh} \mathrm{kg}^{-1}$ remains challenging. This is mostly due to the low capacity of electrode materials such as graphite (372 $\mathrm{Ah} \mathrm{kg}^{-1}$ ), which is believed to be the main bottleneck. ${ }^{12}$, 13 Thus, many high capacity alternatives (e.g., metal oxides ${ }^{14-16}$, Si/C-based anodes, ${ }^{17-19}$ Li-based anode, ${ }^{20-22}$ highvoltage $\mathrm{LiNi}_{1-\mathrm{x}-\mathrm{y}} \mathrm{Co}_{\mathrm{x}} \mathrm{Mn}_{\mathrm{y}} \mathrm{O}_{2}(\mathrm{NCM})$, and spinel oxide cathodes, $\left.{ }^{23-25}\right)$ have been widely evaluated. Besides, the next generation metal-air batteries (e.g., $\mathrm{Li}^{-} \mathrm{O}_{2}$ battery, $\mathrm{Na}-\mathrm{O}_{2}$ battery) is being developed using lithium anode to achieve higher energy density (i.e., without considering the weight of oxygen). ${ }^{26}$ Nonetheless, the achievable practical energy density to date is still below $300 \mathrm{Wh} \mathrm{kg}^{-1}$. A high energy density is even more difficult to achieve in aqueous metal batteries (e.g., zinc (ion) batteries) due to the low working voltage and medium electrode capacity. ${ }^{27}$ The reality has inspired us to consider alternate battery parameters besides electrode material capacity to predict a battery design that can achieve a capacity above $300 \mathrm{Wh} \mathrm{kg}^{-1}$. The list of factors we considered in our analysis includes areal loading density, voltage difference between anode and cathode, initial capacity balance between anode and cathode, and initial Coulombic efficiency. We demonstrate a new empirical model that can be used to estimate the energy density of different batteries by considering several possible factors that can affect energy density.

Model description. The gravimetric energy density (E) of LIBs can be largely determined by their electrode materials: ${ }^{28}$ 


$$
E=\int_{0}^{Q} \frac{U}{m} d Q
$$

where $\mathrm{Q}$ and $\mathrm{m}$ are the capacity and mass of the battery, respectively (Table $\mathbf{1}$ ). The variable $\mathrm{U}$ is the difference in electrode potential between cathode and anode, which is related to the Fermi levels of the anode $\left(\eta_{\mathrm{e}}^{\mathrm{n}}\right)$, cathode $\left(\eta_{\mathrm{e}}^{\mathrm{p}}\right)$ and the elementary electronic charge $(\mathrm{e})(\mathrm{U}=$ $\left.\frac{\eta_{\mathrm{e}}^{\mathrm{n}}-\eta_{\mathrm{e}}^{\mathrm{p}}}{e}\right)$. However, the electrochemical potential of electrons at the vacuum level (i.e., Fermi levels) is not the same as that in an actual phase. In addition, although the voltage difference can be expressed in terms of the difference in the chemical potential of $\mathrm{Li}$ in the two electrodes $\left(\mu_{\mathrm{Li}}^{\mathrm{n}}\right.$ and $\mu_{\mathrm{Li}}^{\mathrm{p}}$ ) when the battery is in a state of equilibrium (i.e., $\mathrm{U}^{\mathbb{e q}}=\frac{\mu_{\mathrm{L}, \tilde{f}}^{\mathrm{n}}-\mu_{\mathrm{Li}}^{\mathrm{p}}}{e}$ ), it is not appropriate to use $U^{\text {eq }}$ to calculate energy density (E) because $U^{\text {eq }}$ changes with the state of charge (SOC) of the battery. Thus, herein an average voltage difference $(\Delta U)$ is introduced to simplify the calculation of $\mathrm{E}$ (i.e., $\mathrm{E}=\frac{\Delta \mathrm{UQ}}{\mathrm{m}}$ ). The variable $\mathrm{Q}$ represents battery capacity which can be calculated from $\mathrm{Q}=\mathrm{C}_{\mathrm{p}} \mathrm{m}_{\mathrm{p}}$ when $\varepsilon_{\mathrm{n}} \geq \varepsilon_{\mathrm{p}}$ (If $\varepsilon_{\mathrm{n}}<\varepsilon_{\mathrm{p}}, Q=C_{p} m_{p_{\varepsilon_{p}}}$, where the $\mathrm{C}_{\mathrm{p}}$ and $\mathrm{m}_{\mathrm{p}}$ are the reversible specific capacity and total mass loading of the cathode, respectively. Thus, the expression for E can be written as:

$$
\mathrm{E}=\frac{\Delta \mathrm{U} \mathrm{C}_{\mathrm{p}} \mathrm{m}_{\mathrm{p}}}{\mathrm{m}}
$$

Herein we introduce a constant $\mathrm{k}$ (where $\mathrm{k}=\frac{\mathrm{m}_{\mathrm{p}}+\mathrm{m}_{\mathrm{n}}}{\mathrm{m}}$ ), defined as the mass fraction of active materials (i.e., cathode $\&$ anode mass divided by total battery mass). Thus, E can be written as below when $m=\frac{m_{p}+m_{n}}{k}$ is input into equation (2):

$$
\mathrm{E}=\mathrm{k} \frac{\Delta \mathrm{U} \mathrm{C}_{\mathrm{p}} \mathrm{m}_{\mathrm{p}}}{\mathrm{m}_{\mathrm{p}}+\mathrm{m}_{\mathrm{n}}}
$$

Note that the $\mathrm{k}$ value is significantly influenced by many parameters, such as the characteristics of electrode materials (e.g., particle size, tap density, and surface area), electrode preparation 
process (e.g., formulas, areal loading density, compaction density), separators, current collectors, and packing process (e.g., electrolyte amount, packing cases). Thus, this k value is a universal constant that can be used in different types of batteries such as the pouch, cylindrical and prismatic batteries. Herein the difference in $\mathrm{k}$ value for different types of batteries results from the different packing cases and structural design, where for example, the packing case should be heavier for prismatic batteries (i.e., aluminum case), resulting in the $\mathrm{k}$ value of prismatic batteries is generally lower than that of pouch and cylinder batteries. Note that the $\mathrm{k}$ value is hard to be calculated directly at present because it involves many parameters discussed above, but we can get an empirical value by the actual energy densities of current LIBs, as discussed in the next section.

Finally, the initial capacity balance between anode and cathode $(\chi)$ is introduced (where $\left.\chi=\frac{\mathrm{C}_{\mathrm{n}} \mathrm{m}_{\mathrm{n}} \varepsilon_{\mathrm{p}}}{\mathrm{C}_{\mathrm{p}} \mathrm{m}_{\mathrm{p}} \varepsilon_{\mathrm{n}}}\right)$, the $\mathrm{E}$ can be written as below when $\mathrm{m}_{\mathrm{n}}=\chi \frac{\varepsilon_{\mathrm{n}} \mathrm{C}_{\mathrm{p}} \mathrm{m}_{\mathrm{p}}}{\varepsilon_{\mathrm{p}} \mathrm{C}_{\mathrm{n}}}$ is input into equation (3):

$$
\mathrm{E}=\mathrm{k} \Delta \mathrm{U} \frac{1}{\frac{1}{\mathrm{C}_{\mathrm{p}}}+\chi_{\varepsilon_{\mathrm{p}}}^{\varepsilon_{\mathrm{n}}} \frac{1}{\mathrm{c}_{\mathrm{n}}}}
$$

in which $\mathrm{k}, \Delta \mathrm{U}, \mathrm{C}_{\mathrm{p}}$ and $\mathrm{C}_{\mathrm{n}}, \chi, \varepsilon_{\mathrm{n}}$ and $\varepsilon_{\mathrm{p}}$ factors are considered (Figure 1). The value of $\chi$ and $\chi$ $\frac{\varepsilon_{\mathrm{n}}}{\varepsilon_{\mathrm{p}}}$ higher than 1 (i.e., $\chi>1$ and $\chi_{\varepsilon_{\mathrm{p}}}^{\varepsilon_{\mathrm{n}}}>1$ ) can be defined as anode excess (i.e., the capacity of anode is higher than that of cathode in battery design). For example, the $\chi_{\varepsilon_{\mathrm{p}}}^{\varepsilon_{\mathrm{n}}}=1.1\left(\chi_{\varepsilon_{\mathrm{p}}}^{\varepsilon_{\mathrm{n}}}=\frac{\mathrm{C}_{\mathrm{n}} \mathrm{m}_{\mathrm{n}}}{\mathrm{C}_{\mathrm{p}} \mathrm{m}_{\mathrm{p}}}\right)$ means that the reversible capacity of anode is $10 \%$ higher than that of the cathode, which is required in most current battery designs.

Effect of $\mathbf{k}$ and $\boldsymbol{\Delta} \mathbf{U}$. The universality of the model and the factors affecting battery energy density are verified in the current LIBs system. The relationship between E, on the one hand, and $\mathrm{k}$ and $\Delta \mathrm{U}$ on the other hand is shown in Figure $2 \mathrm{a}$, in which the $\mathrm{C}_{\mathrm{p}}$ and $\mathrm{C}_{\mathrm{n}}$ are taken as $150 \mathrm{Ah} \mathrm{kg}^{-1}$ (e.g., typical $\mathrm{LiCoO}_{2}$ or $\mathrm{LiFePO}_{4}$ cathode) and $340 \mathrm{Ah} \mathrm{kg}^{-1}$ (e.g., graphite anode), 
respectively. Particularly, the value of $\chi_{\varepsilon_{\mathrm{p}}}^{\varepsilon_{\mathrm{n}}}$ (i.e., capacity balance) can be taken as 1.1 because the initial Coulombic efficiency of graphite is close to that of the cathode (i.e., $\varepsilon_{\mathrm{n}} \approx \varepsilon_{\mathrm{p}}$ ). The slightly higher capacity of the anode side $(\sim 10 \%)$ is used to avoid the lithium plating and/or dendrite formation on the anode surface in the first charging process and over the life of the battery. ${ }^{29}$ Based on the above definition, we find that $\mathrm{E}$ increases with the $\mathrm{k}$ value, albeit at a faster when the $\Delta \mathrm{U}$ becomes large (Figure S1). It is important to note that the $\mathrm{k}$ values of commercialized $\mathrm{C} \| \mathrm{LiCoO}_{2}$ battery $(\Delta \mathrm{U}=3.7 \mathrm{~V})$ and $\mathrm{C} \| \mathrm{LiFePO}_{4}$ battery $(\Delta \mathrm{U}=3.3 \mathrm{~V})$ are about $0.5-0.55$ and $0.45-0.5$ according to the measured energy density of actual batteries, respectively (Figure S1). Thus, we can use these empirical values (i.e., $\mathrm{k}=0.45-0.55$ ) to estimate the energy density of a new battery with different electrode materials and capacities. Note that the $\mathrm{k}$ value of $\mathrm{C} \| \mathrm{LiCoO}_{2}$ or $\mathrm{C} \| \mathrm{NCM}$ is generally higher than that of $\mathrm{C} \| \mathrm{LiFePO}_{4}$ in the same battery type. This is because the characteristics of $\mathrm{LiCoO}_{2}$ or $\mathrm{NCM}$ (e.g., particle size, surface area, and tap density and compaction density) are better than those of $\mathrm{LiFePO}_{4}$. This result indicates that the characteristics of electrode materials can affect the $\mathrm{k}$ value significantly. Moreover, the k value can be increased by reducing the thickness (i.e., weight) of the current collectors (i.e., $\mathrm{Al}, \mathrm{Cu}$ foil) and separator, as they will decrease the overall battery mass (m). This might be more efficient than increasing the anode capacity to achieve higher $\mathrm{E}$ value in some cases. For example, the E value can increase from $137 \mathrm{Wh} \mathrm{kg}^{-1}$ to $167 \mathrm{Wh} \mathrm{kg}^{-1}$ in the case of $\mathrm{C} \| \mathrm{LiFePO}_{4}$ battery when the k value increases from 0.4 to 0.5 (Figure S2a). In contrast, the anode capacity has to be increased to $\sim 2000 \mathrm{Ah} \mathrm{kg}^{-1}$ to achieve the same E value (Figure S2b). Actually, it is difficult to design a commercial anode such as the $\mathrm{Si} / \mathrm{C}$ anode with $2000 \mathrm{Ah} \mathrm{kg}^{-1}$ capacity based on the current technologies, particularly since we have to retain stable operation over thousands of cycles. Thus, more performance metrics need to be considered besides lithium-ion storage capacity. 
There is still plenty of room to increase $\mathrm{E}$ through increasing $\mathrm{k}$. This is because the k value is still far below the maximum achievable limit (Figure 2b). The value of $\mathrm{k}$ can be increased fast by increasing the ratio of total active materials $\left(\mathrm{m}_{\mathrm{a}}\right)$ to non-active materials $\left(\mathrm{m}_{\text {non-a }}\right)$ in the battery (i.e., $\frac{m_{a}}{m_{n o n-a}}, m_{a}=m_{p}+m_{n}, m_{n o n-a}=m-m_{a}$ ). For example, the energy density of C || NCM811 battery can reach $300 \mathrm{Wh} \mathrm{kg}^{-1}$ (Figure S2c) if the k value can be increased from the current value of 0.5 to 0.7 . This can be done by increasing the $\frac{\mathrm{m}_{\mathrm{a}}}{\mathrm{m}_{\text {non-a }}}$ value from 1.0 to 2.33, wherein $\mathrm{m}_{\mathrm{a}}$ increases $40 \mathrm{wt} \%$ while the $\mathrm{m}_{\text {non-a }}$ decreases $40 \mathrm{wt} \%$. Thus, another strategy to increase the $\mathrm{k}$ value is increasing the proportion of total active materials in the battery (i.e., the areal loading density of the electrode). ${ }^{30}$ However, a high areal loading density means a thick electrode, which might induce increased polarization and resistance in the battery. ${ }^{31}$ Therefore, increasing the conductivity and compaction density of the electrode such as using single-crystal materials (e.g., single-crystal NCM cathodes) becomes ever more important to overcome these disadvantages. Note that the high compaction density can also reduce the amount of electrolytes and thus increase the k value. ${ }^{32}$ Besides, in-situ modification of anode (e.g., Si-based anode) by ultrathin carbon network (e.g, carbon nanotubes ${ }^{17}$ ) might further reduce the amount of conductive carbon and binders needed in the electrode; meanwhile, an integrated electrode using ultrathin and/or ultralight current collector to load highly compacted materials can be expected to increase the $\mathrm{k}$ value further. In contrast, the features of nanostructures (e.g., nanoparticle morphology), ${ }^{33}$ rich porosity, ${ }^{34}$ and high surface area ${ }^{35}$ of those high capacity anode materials might have negative effects. This is because these materials are difficult to be compacted and wetted within the battery.

In contrast, the $\Delta \mathrm{U}$ value is difficult to increase by optimizing the electrode process because $\Delta \mathrm{U}$ is determined by the intrinsic properties of the cathode and anode. We can only choose a cathode with the higher chemical potential for the $\mathrm{Li}^{+}$-intercalation and an anode with 
lower chemical potential for the $\mathrm{Li}^{+}$-(de)intercalation. For example, $\Delta \mathrm{U}$ of the battery can be increased from 3.9 V to $4.6 \mathrm{~V}$ if we use high-voltage $\mathrm{LiNi}_{0.5} \mathrm{Mn}_{1.5} \mathrm{O}_{4}\left(4.7 \mathrm{~V} \mathrm{vs}\right.$. $\left.\mathrm{Li} / \mathrm{Li}^{+}\right)$to replace $\mathrm{LiMn}_{2} \mathrm{O}_{4}\left(4.0 \mathrm{~V}\right.$ vs. $\left.\mathrm{Li} / \mathrm{Li}^{+}\right)$as cathode. ${ }^{36,37}$ The corresponding $\mathrm{E}$ value can be increased from 196.3 $\mathrm{Wh} \mathrm{kg}^{-1}$ to $231.5 \mathrm{Wh} \mathrm{kg}^{-1}$, where the $\mathrm{k}, \mathrm{C}_{\mathrm{n}}, \mathrm{C}_{\mathrm{p}}$, and $\chi_{\varepsilon_{\mathrm{p}}}^{\varepsilon_{\mathrm{n}}}$ values are taken as $0.55,340 \mathrm{Ah}$ $\mathrm{kg}^{-1}, 130 \mathrm{Ah} \mathrm{kg}^{-1}$ and 1.1, respectively (Figure S3). In addition, increasing the charged cut-off voltage can increase $\Delta U$ and deliver more capacity for metal layered oxide cathodes such as $\mathrm{LiCoO}_{2}$ and NCM. ${ }^{38}$ However, the situation for the anodes is more complex (Figure 2c). The metal oxide-based anodes have been proposed to replace the graphite anode $\left(\sim 340 \mathrm{Ah} \mathrm{kg}^{-1}\right)$ due to their high lithium storage capacity $\left(>800 \mathrm{Ah} \mathrm{kg}^{-1}\right) .{ }^{39}$ However, the chemical potential for the $\mathrm{Li}^{+}$-(de)intercalation of these metal oxide anodes (e.g., $\mathrm{Co}_{3} \mathrm{O}_{4} / \mathrm{C}$ ) also increases (e.g., $\sim 1.7 \mathrm{~V}$ vs. $0.1 \mathrm{~V}$ for graphite) (Figure 2d). ${ }^{40}$ This is a large trade-off because $\Delta \mathrm{U}$ decreases significantly to $\sim 2.0 \mathrm{~V}$ (for a metal oxide $\| \mathrm{NCM} 811, \mathrm{LiNi}_{0.8} \mathrm{Co}_{0.1} \mathrm{Mn}_{0.1} \mathrm{O}_{2}$ battery), where the calculated E value becomes only about $172.5 \mathrm{Wh} \mathrm{kg}^{-1}$ (Table S1) assuming $\mathrm{k}, \mathrm{C}_{\mathrm{n}}, \mathrm{C}_{\mathrm{p}}$, and $\chi_{\varepsilon_{\mathrm{p}}}^{\frac{\varepsilon_{\mathrm{n}}}{2}}$ values of $0.55,800 \mathrm{Ah} \mathrm{kg}^{-1}, 200 \mathrm{Ah} \mathrm{kg}^{-1}$, and 1.1, respectively. This result demonstrates that the $\mathrm{E}$ value of the battery using metal oxide anode is much lower than $240 \mathrm{Wh} \mathrm{kg}^{-1}$ which can be achieved in the case of C || NCM811 battery (Table S1). Moreover, the situation might be even worse due to the low electrical conductivity, high surface area, rich porosity, and low Coulombic efficiency of the metal oxide anodes.

Effect of $\mathbf{C}_{\mathbf{n}}, \mathbf{C}_{\mathbf{p}}$, and $\chi_{\varepsilon_{\mathbf{p}}}^{\boldsymbol{\varepsilon}_{\mathbf{n}}}$. The anode capacity $\left(\mathrm{C}_{\mathrm{n}}\right)$ and cathode capacity $\left(\mathrm{C}_{\mathrm{p}}\right)$ are further analyzsed in Figure 3a, setting the parameters $\mathrm{k}, \Delta \mathrm{U}$, and $\chi_{\varepsilon_{\mathrm{p}}}^{\varepsilon_{\mathrm{n}}}$ as $0.55,3.3 \mathrm{~V}$, and 1.1, respectively. We find that the $E$ value shows a parabolic dependence on both the $C_{p}$ and $C_{n}$. This means that the increase in E value slows down with increasing cathode or anode capacity when one of them is fixed (Figure 3b). Particularly, the parabolic feature of the $E\left(C_{n}\right)$ function 
is more prominent compared to that of the $\mathrm{E}\left(\mathrm{C}_{\mathrm{p}}\right)$ (Figure $\left.3 \mathrm{~b}-\mathrm{c}\right)$. This trend occurs because $\frac{1}{\mathrm{C}_{\mathrm{p}}}>$ $\frac{1.1}{C_{n}}$. This result reveals that the E value can be more effectively enhanced by increasing the cathode capacity. For example, the E value can increase quickly from $297.5 \mathrm{Wh} \mathrm{kg}^{-1}$ to 321.5 Wh kg-1 when $C_{p}$ increases from $200 \mathrm{Ah} \mathrm{kg}^{-1}$ to $220 \mathrm{Ah} \mathrm{kg}^{-1}$ (i.e., $10 \%$ increment) with $\mathrm{C}_{\mathrm{n}}$ kept constant at $1000 \mathrm{Ah} \mathrm{kg}^{-1}$ (Figure 3c). In contrast, $\mathrm{C}_{\mathrm{n}}$ needs to be increased from $1000 \mathrm{Ah} \mathrm{kg-}^{-}$ ${ }^{1}$ to $1700 \mathrm{Ah} \mathrm{kg}^{-1}$ (i.e., $70.0 \%$ increment) to achieve the same $\mathrm{E}$ value with $\mathrm{C}_{\mathrm{p}}$ held constant at $200 \mathrm{Ah} \mathrm{kg}^{-1}$ (Figure 3b). This result reveals that the complex electrode behavior must be considered for designing a high energy density battery. Thus, we propose a design strategy for LIBs having an energy density ranging from $150 \mathrm{Wh} \mathrm{kg}^{-1}$ to $400 \mathrm{Wh} \mathrm{kg}^{-1}$, in which the battery systems and parameters are presented in Figure 3d. For example, $\mathrm{C}_{\mathrm{n}}$ of the $\mathrm{Si} / \mathrm{C}$ anode needs to be increased to $1100 \mathrm{Ah} \mathrm{kg}^{-1}$ in the $\mathbf{S i} / \mathbf{C} \| \mathbf{N C M 8 1 1}$ battery to achieve an energy density beyond $300 \mathrm{Wh} \mathrm{kg}^{-1}$, in which the $\mathrm{C}_{\mathrm{p}}, \mathrm{k}, \Delta \mathrm{U}$, and $\chi_{\varepsilon_{\mathrm{p}}}^{\varepsilon_{\mathrm{n}}}$ are set as $200 \mathrm{Ah} \mathrm{kg}^{-1}, 0.55,3.3 \mathrm{~V}$, and 1.1 , respectively.

Note that the above discussion is based on the conditions of $\chi_{\varepsilon_{\mathrm{p}}}^{\varepsilon_{\mathrm{n}}}=1.1, \varepsilon_{\mathrm{n}}>\varepsilon_{\mathrm{p}}$, and $\frac{\varepsilon_{\mathrm{n}}}{\varepsilon \mathrm{p}} \approx 1$ (e.g., graphite anode and NCM cathode). Actually, decreasing the $\chi_{\varepsilon_{\mathrm{p}}}^{\varepsilon_{\mathrm{n}}}$ value can also increase E, but several points have to be noted when considering the effect of $\chi, \varepsilon_{\mathrm{n}}$, and $\varepsilon_{\mathrm{p}}$ on the $\chi \frac{\varepsilon_{\mathrm{n}}}{\varepsilon_{\mathrm{p}}}$ value: (i) the $\chi_{\varepsilon_{\mathrm{p}}}^{\varepsilon_{\mathrm{n}}}$ value can be decreased by decreasing $\chi$ when $\frac{\varepsilon_{\mathrm{n}}}{\varepsilon_{\mathrm{p}}} \approx 1$ (e.g., C \| NCM811 battery, the $\varepsilon_{\mathrm{n}}$ is $90 \%-92 \%$, the $\varepsilon_{\mathrm{p}}$ is $88 \%-90 \%$ ). But this approach might induce the lithium plating and/or dendrite formation on the anode surface during the first charging; ${ }^{41}$ (ii) the $\chi_{\varepsilon_{\mathrm{p}}}^{\varepsilon_{\mathrm{n}}}$ value can be decreased if $\varepsilon_{\mathrm{n}}<\varepsilon_{\mathrm{p}}$ (e.g., Si/C $\|$ NCM811 battery, $\varepsilon_{\mathrm{n}}<75 \%$ ). ${ }^{42}$ However, the actual energy density can be decreased due to the high irreversibility of the anode (i.e., low $\varepsilon_{\mathrm{n}}$ ). This 
is because the proposed model would change to $\mathrm{E}=\mathrm{k} \Delta \mathrm{U} \frac{\frac{\varepsilon_{\mathrm{n}}}{\varepsilon_{\mathrm{p}}}}{\frac{1}{\overline{\mathrm{p}}_{\mathrm{p}}}+\chi_{\frac{\mathrm{n} 1}{\mathrm{p}_{\mathrm{p}} \mathrm{C}_{\mathrm{n}}}}}$, in which the decreased $\frac{\varepsilon_{\mathrm{n}}}{\varepsilon_{\mathrm{p}}}$ value cannot deliver high energy density. Thus, the $\varepsilon_{\mathrm{n}}$ of Si-based anode need to be increased up to $90 \%$ to match with the NCM cathode for high energy density battery; (iii) In contrast, the $\chi_{\varepsilon_{\mathrm{p}}}^{\varepsilon_{\mathrm{n}}}$ value can be increased if the $\varepsilon_{\mathrm{n}}$ is much higher than $\varepsilon_{\mathrm{p}}$ (e.g., C $\|$ Li-rich Mn-based oxides battery, $\left.\varepsilon_{\mathrm{p}}<75 \%\right) .{ }^{43}$ Obviously, the E value would be decreased due to the increased $\frac{\varepsilon_{\mathrm{n}}}{\varepsilon_{\mathrm{p}}}$ value. Therefore, the $\varepsilon_{\mathrm{p}}$ of the cathode also needs to be increased by nearly $90 \%$ or using an anode with low $\varepsilon_{\mathrm{n}}$ (e.g. Si/C anode, $\varepsilon_{\mathrm{n}}<75 \%$ ). Therefore, optimizing the value of $\chi, \varepsilon_{\mathrm{n}}, \varepsilon_{\mathrm{p}}$ and their relationship (i.e., $\chi_{\varepsilon_{\mathrm{p}}}^{\varepsilon_{\mathrm{n}}}=1.1, \varepsilon_{\mathrm{n}}>\varepsilon_{\mathrm{p}}$, and $\frac{\varepsilon_{\mathrm{n}}}{\varepsilon \mathrm{p}} \approx 1$ ) is very important for minimizing the lithium loss in initial cycles and improving energy density.

We also considered the case of cathode excess (i.e., $\chi \leq 1$ and $\chi_{\varepsilon_{\mathrm{p}}}^{\varepsilon_{\mathrm{n}}}<1$, where the capacity of cathode is to be present in equal or higher than that of the anode). Note that this situation has to be avoided for the anodes (e.g., graphite and $\mathrm{Si}$ ) with low lithiation potential which is close to the lithium plating potential $\left(\mathrm{Li} / \mathrm{Li}^{+}\right)$. This is because the low lithiation potential can induce lithium plating on the anode surface causing safety issues. In contrast, this situation might exist when the $\mathrm{Li}_{4} \mathrm{Ti}_{5} \mathrm{O}_{12}$ (LTO) is used as anode, because the lithium is not easy to be plated on the LTO surface due to the high lithiation potential of LTO $\left(1.5 \mathrm{~V} \mathrm{vs}\right.$. $\left.\mathrm{Li} / \mathrm{Li}^{+}\right)$. Thus, in such a situation, the capacity of the battery is determined by the anode (i.e., $Q=C_{n} m_{n}, E=k$ $\left.\frac{C_{n} m_{n}}{m_{n}+m_{p}}\right)$. Herein $E$ can be written as $E=k \Delta U \frac{1}{\frac{1}{C_{n}}+\frac{\varepsilon_{p}}{\chi \varepsilon_{n}} \frac{1}{C_{p}}}$ when $\chi=\frac{C_{n} m_{n} \varepsilon_{p}}{C_{p} m_{p} \varepsilon_{n}}$ is input into the equation of $\mathrm{E}=\mathrm{k} \frac{\mathrm{C}_{\mathrm{n}} \mathrm{m}_{\mathrm{n}}}{\mathrm{m}_{\mathrm{n}}+\mathrm{m}_{\mathrm{p}}}$. Thus, the value of $\frac{\varepsilon_{\mathrm{p}}}{\chi \varepsilon_{\mathrm{n}}}$ is equal to $1.1\left(\frac{\varepsilon_{\mathrm{p}}}{\chi \varepsilon_{\mathrm{n}}}=\frac{\mathrm{C}_{\mathrm{p}} \mathrm{m}_{\mathrm{p}}}{\mathrm{C}_{\mathrm{n}} \mathrm{m}_{\mathrm{n}}}=1.1\right)$ when we design there is $10 \%$ excess cathode. This is similar to the situation when we design there is $10 \%$ excess anode $\left(\mathrm{E}=\mathrm{k} \Delta \mathrm{U} \frac{1}{\frac{1}{C_{\mathrm{p}}}+\chi \frac{\varepsilon_{\mathrm{n}}}{\varepsilon_{\mathrm{p}}} \frac{1}{C_{\mathrm{n}}}}, \chi_{\varepsilon_{\mathrm{p}}}^{\varepsilon_{\mathrm{n}}}=\frac{C_{n} m_{n}}{C_{p} m_{p}}=1.1\right)$. We find that the difference of the $\mathrm{E}$ value in these two 
situations is small if $\mathrm{C}_{\mathrm{p}}$ is close to $\mathrm{C}_{\mathrm{n}}$ (e.g., $\mathrm{C}_{\mathrm{p}}=180 \mathrm{mAh} \mathrm{g}^{-1}$ for the NCM622, $\mathrm{C}_{\mathrm{n}}=160 \mathrm{mAh} / \mathrm{g}$ for the LTO). However, we have to note that setting the values of $\chi$ and $\frac{\varepsilon_{\mathrm{p}}}{\chi \varepsilon_{\mathrm{n}}}$ or $\left(\chi_{\varepsilon_{\mathrm{p}}}^{\varepsilon_{\mathrm{n}}}\right)$ in the battery design need to consider the attenuation efficiency of the cathode and anode. In this case, the values of $\chi<1$ and $\frac{\varepsilon_{\mathrm{p}}}{\chi \varepsilon_{\mathrm{n}}}>1$ can be set when the LTO is used as the anode, because the attenuation efficiency of LTO is much smaller than that of the NCM cathode due to the high structural stability of LTO. ${ }^{44}$ In contrast, we need to increase the $\chi$ value (i.e., $\chi>1$ and $\chi_{\varepsilon_{\mathrm{p}}}^{\varepsilon_{\mathrm{n}}}>1$ ) to prolong the lifespan of the battery if the attenuation efficiency of the anode is larger than that of the cathode, as discussed later in the model of lithium metal batteries (e.g., Li/NCM battery).

Model Applicability Beyond LIBs. Our proposed model can be applied to the other battery systems, such as Li-S and Li-metal batteries, in which lithium metal is used as anode to achieve higher energy densities. Firstly, the parameter $\frac{\varepsilon_{n}}{\varepsilon p}$ can be defined as 1.0 in these systems because the lithium is usually present in excess in the battery to ensure high cycling stability. However, the $\mathrm{k}$ value is expected to be low in Li-S battery. This is because the low electrical conductivity of sulfur does not allow high loading, and the battery can expire quickly due to excessive lithium polysulfide accumulation. ${ }^{45}$ Thus, the effect of $k$ and $\chi$ on E value is shown in Figure 4a, where the $\Delta \mathrm{U}, \mathrm{C}_{\mathrm{p}}$, and $\mathrm{C}_{\mathrm{n}}$ are set as $2.0 \mathrm{~V}, 1000 \mathrm{Ah} \mathrm{kg}^{-1}$, and $3860 \mathrm{Ah} \mathrm{kg}^{-1}$, respectively. We find that $\mathrm{E}$ can increase from $338 \mathrm{Wh} \mathrm{kg}^{-1}$ to $450 \mathrm{Wh} \mathrm{kg}^{-1}$ when $\mathrm{k}$ value increases from 0.3 to 0.4 (with $\chi$ value is set as 3.0 (Figure $4 \mathrm{~b}$ ). Besides, E can increase from $344 \mathrm{Wh} \mathrm{kg}^{-1}$ to 461 Wh kg-1 when $\chi$ decreases from 4.0 to 2.0 (Figure 4c), or from $345.3 \mathrm{Wh} \mathrm{kg}^{-1}$ to $434.6 \mathrm{Wh} \mathrm{kg}^{-1}$ when $\mathrm{C}_{\mathrm{p}}$ increases from $800 \mathrm{Ah} \mathrm{kg}^{-1}$ to $1200 \mathrm{Ah} \mathrm{kg}^{-1}$ (Figure 4d). Thus, a reasonable design strategy for Li-S battery to achieve energy density from $300 \mathrm{Wh} \mathrm{kg}^{-1}$ to $500 \mathrm{Wh} \mathrm{kg}^{-1}$ is presented in Figure S4. We find that the energy density can reach $300 \mathrm{Wh} \mathrm{kg}^{-1}$ when the $\chi \leq 1.5, \mathrm{C}_{\mathrm{p}} \geq 800 \mathrm{Ah} \mathrm{kg}^{-1}$, and $\mathrm{k} \geq 0.25$. Note that the increased $\mathrm{k}$ value in Li-S batteries might 
be challenging compared to that in LIBs because at least 2-3 times more electrolyte is used in most Li-S batteries. ${ }^{46-49}$ Thus, mitigating the dissolution of lithium polysulfide and/or using specific cathode such as the sulfurized polyacrylonitrile (i.e., thiyl radical reaction mechanism without the formation of polysulfide) $)^{50}$ might become critical to develop the higher energy density Li-S batteries.

In contrast, $\mathrm{k}$ values above 0.55 are easy to achieve for the Li-metal battery using lithium layered oxide cathode (e.g., NCM) due to the high compaction density and loading of NCM in the electrode. ${ }^{51}$ Thus, the dependence of $\mathrm{E}$ on $\chi$ and $\mathrm{C}_{\mathrm{p}}$ is described in Figure 5a, where the k, $\Delta \mathrm{U}$, and $\mathrm{C}_{\mathrm{n}}$ parameters are fixed at $0.55,3.7 \mathrm{~V}$, and $3860 \mathrm{Ah} \mathrm{kg}^{-1}$, respectively. Figure $5 \mathrm{~b}$ describes the variation of $E$ with $\chi$ when the $C_{p}$ is fixed at $200 \mathrm{Ah} \mathrm{kg}^{-1}$. We find that $\mathrm{E}$ can increase from $337 \mathrm{Wh} \mathrm{kg}^{-1}$ to $369 \mathrm{Wh} \mathrm{kg}^{-1}$ when $\chi$ is reduced from 4.0 to 2.0. Besides, the $\mathrm{E}$ values can increase from $321 \mathrm{Wh} \mathrm{kg}^{-1}$ to $382 \mathrm{Wh} \mathrm{kg}^{-1}$ when $\mathrm{C}_{\mathrm{p}}$ increases from $180 \mathrm{Ah} \mathrm{kg}^{-1}$ to $220 \mathrm{Ah} \mathrm{kg}^{-1}$ (Figure 5c). Therefore, the achievable energy density of Li $\|$ NCM battery can reach beyond $300 \mathrm{Wh} \mathrm{kg}^{-1}$ when the $\chi \leq 4.7, \mathrm{C}_{\mathrm{p}} \geq 180 \mathrm{Ah} \mathrm{kg}^{-1}$, and $\mathrm{k} \geq 0.55$ (Figure 5d). Based on the proposed empirical model, several strategies can be used to improve the energy density of batteries: i) materials selection: high capacity electrodes (e.g., Si-based anode, nickel-rich NCM), high areal density of active materials in the electrode, high tap density such as using single-crystal materials, low surface area to reduce the used electrolyte amount, ultralight current collector (e.g., $\mathrm{Cu}<6 \mu \mathrm{m}$ ) or separator; ii) cell design: high energy density battery system such as the C || NCM811 and Li || NCM battery (Figure 3d, Figure 5), where the pouch cell is better because the weight of the packing case (i.e., aluminum-plastic film) is lighter; iii) process optimization: high pressure rolling process for high compaction density, ideal values of $\chi$ and $\chi \varepsilon_{\varepsilon_{\mathrm{p}}}^{\varepsilon_{\mathrm{n}}}$ or $\left(\frac{\varepsilon_{\mathrm{p}}}{\chi \varepsilon_{\mathrm{n}}}\right)$ for the full utilization of the electrode. 
In addition, our proposed model can be further extended to Na-ion batteries (NIBs) and potassium ion batteries (KIBs) since they exhibit the same rocking chair mechanism. We find that the E value of NIBs is much lower than that of LIBs due to lower $\Delta \mathrm{U}$ and capacity of the cathode and anode. ${ }^{52,53}$ The dependence of $E$ on $C_{p}$ and $C_{n}$ of NIBs is described in Figure 6a, in which $\mathrm{k}, \Delta \mathrm{U}$, and $\chi_{\varepsilon_{\mathrm{p}}}^{\varepsilon_{\mathrm{n}}}$ are fixed at $0.5,3.2$, and 1.1 , respectively. The $\mathrm{k}$ value was set at 0.5 based on the empirical value of LIBs (Figure 2, Figure S1). Thus, we can estimate the energy density of the batteries when we set the parameters in a rational value accordingly (e.g., $\Delta \mathrm{U}$, $\mathrm{C}_{\mathrm{p}}$ and $\mathrm{C}_{\mathrm{n}}, \chi, \varepsilon_{\mathrm{n}}$ and $\varepsilon_{\mathrm{p}}$ ). Then, we could consider how to increase the $\mathrm{k}$ value by optimizing the electrode materials (e.g., particle size, surface area, and tap density, etc.), electrode preparation and battery design when the actual $\mathrm{E}$ value has a large deviation to the estimated value. For example, the E values can increase from $131.5 \mathrm{Wh} \mathrm{kg}^{-1}$ to $169.3 \mathrm{Wh} \mathrm{kg}^{-1}$ when $\mathrm{C}_{\mathrm{n}}$ increases from $200 \mathrm{Ah} \mathrm{kg}^{-1}$ to $400 \mathrm{Ah} \mathrm{kg}^{-1}$ if the $\mathrm{C}_{\mathrm{p}}$ value is fixed at $150 \mathrm{Ah} \mathrm{kg}^{-1}$ (Figure 6b). Alternatively, the energy density of NIBs can increase from $169.9 \mathrm{Wh} \mathrm{kg}^{-1}$ to $206.5 \mathrm{Wh} \mathrm{kg}^{-1}$ when the $C_{p}$ increases from $150 \mathrm{Ah} \mathrm{kg}^{-1}$ to $200 \mathrm{Ah} \mathrm{kg}^{-1}$ if the $\mathrm{C}_{\mathrm{n}}$ value is fixed at $400 \mathrm{Ah} \mathrm{kg}^{-1}$ (Figure 6c) ${ }^{54,55}$ In the case of KIBs, the E values can increase from $72.2 \mathrm{Wh} \mathrm{kg}^{-1}$ to $160.6 \mathrm{Wh}$ $\mathrm{kg}^{-1}$ when $\mathrm{C}_{\mathrm{p}}$ increases from $50 \mathrm{Ah} \mathrm{kg}^{-1}$ to $150 \mathrm{Ah} \mathrm{kg}^{-1}$ (Figure 6d-e), where $\mathrm{k}, \Delta \mathrm{U}, \mathrm{C}_{\mathrm{n}}$, and $\chi_{\varepsilon_{\mathrm{p}}}^{\frac{\varepsilon_{\mathrm{n}}}{2}}$ are fixed at $0.5,3.5,260 \mathrm{Ah} \mathrm{kg}^{-1}$ and 1.1 , respectively. ${ }^{56} \mathrm{We}$ further estimate the energy density of KIBs using our model in Table S2-S3. The energy density may be boosted from its current low values $\left(\sim 100 \mathrm{Wh} \mathrm{kg}^{-1}\right)$ through optimization of the $\mathrm{k}, \mathrm{C}_{\mathrm{p}}, \mathrm{C}_{\mathrm{n}}$, and $\chi_{\varepsilon_{\mathrm{p}}}^{\varepsilon_{\mathrm{n}}}$ values in the future. 57 ${ }^{60}$ Particularly, the $\mathrm{K}^{+}$ion exhibit a faster rate of diffusion in electrolyte solution and higher molar conductivity compared to $\mathrm{Na}^{+}$and $\mathrm{Li}^{+}$due to the smallest Stokes radii in solutions (e.g., PC) (Figure 6f), which might enable the KIBs with high rate capabilities. ${ }^{60}$ Although it seems challenging for NIBs and KIBs to go beyond $300 \mathrm{Wh} \mathrm{kg}^{-1}$ based on the current sodium or potassium electrode materials due to the large radii of $\mathrm{Na}^{+}$and $\mathrm{K}^{+}$, the advantages of low-cost, 
geographical distribution, and abundance of $\mathrm{Na} / \mathrm{K}$ compared to $\mathrm{Li}$, may make NIBs and $\mathrm{KIBs}$ attractive. Particularly, we believe this would be more attractive when the high capacity electrode (e.g., alloying anode ${ }^{61}$ ) can be designed and stabilized readily.

In this work, we present an empirical model that can be used to estimate the energy density of various types of batteries. The model input parameters include several important factors besides the electrode material storage capacity. Based on our model, we demonstrate several reasonable approaches for designing C || NCM811, Si/C || NCM, Li-S, and Li || NCM batteries with energy density higher than $300 \mathrm{Wh} \mathrm{kg}^{-1}$. Besides, we show the feasibility of our model to the current NIBs and KIBs. Our empirical model provides a simple yet informative approach for straightforward guidelines to design higher energy density batteries. 
Table 1 Abbreviation and definition in empirical model for the design of batteries. ${ }^{\dagger}$ 
a

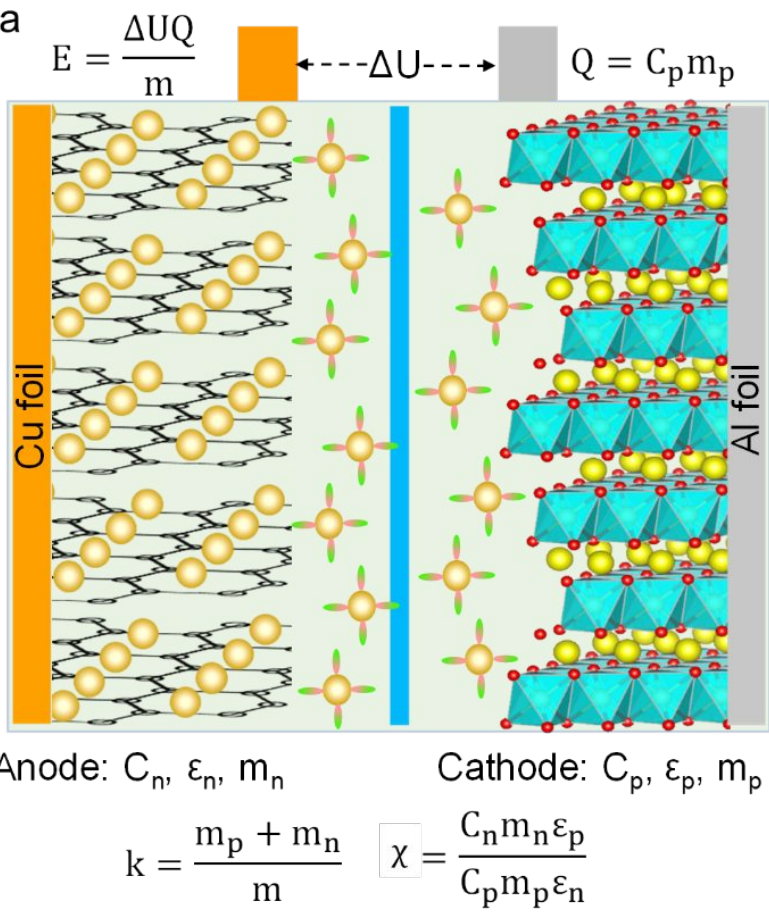

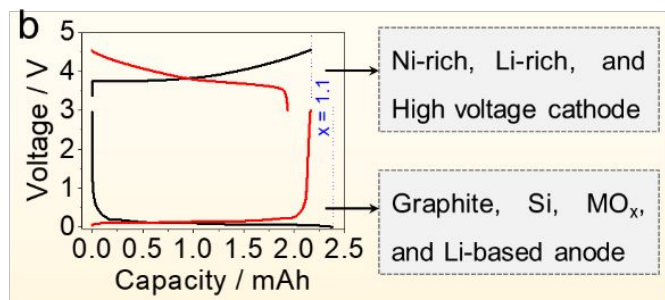

New materials design

$$
E=\mathrm{k} \Delta \mathrm{U} \frac{1}{\frac{1}{\mathrm{C}_{\mathrm{p}}}+\chi \frac{\varepsilon_{\mathrm{n}}}{\varepsilon_{\mathrm{p}}} \frac{1}{\mathrm{C}_{\mathrm{n}}}}
$$

High energy battery design

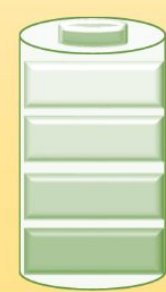

Parameter's optimization in current LIBS

Next generation Li-S, Li-

$\mathrm{O}_{2}$, and Li-metal battery

Figure 1. Schematic illustration of LIB and the factors that can affect its energy density.

(a) Battery configuration and parameters. (b) A guideline for using our simple model to design battery parameters to achieve higher energy density. 
a

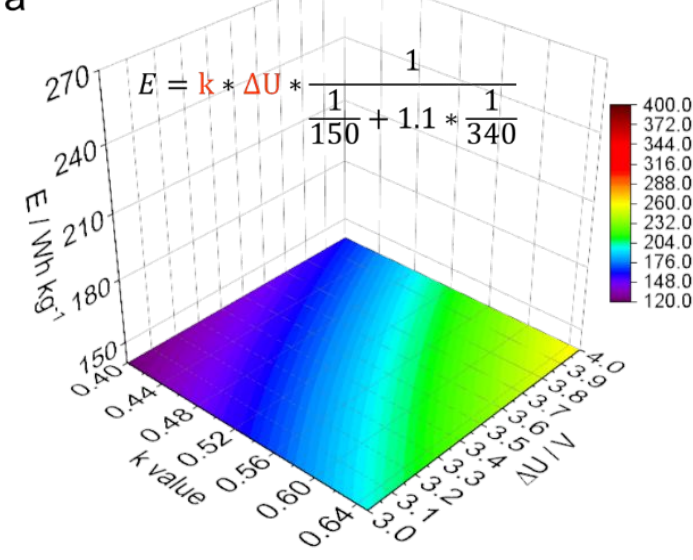

C

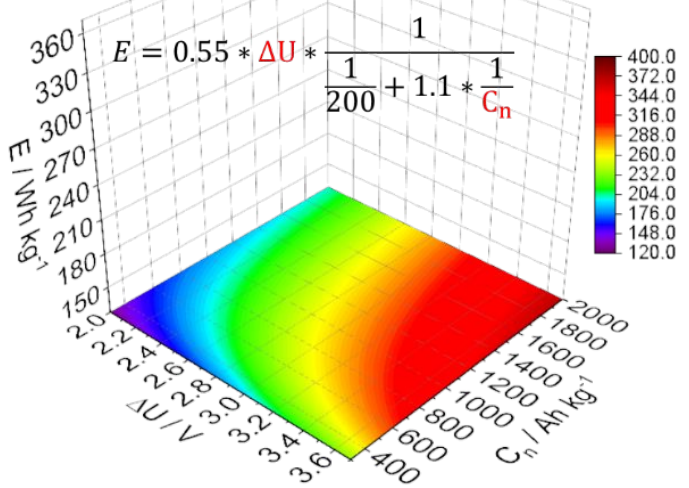

b
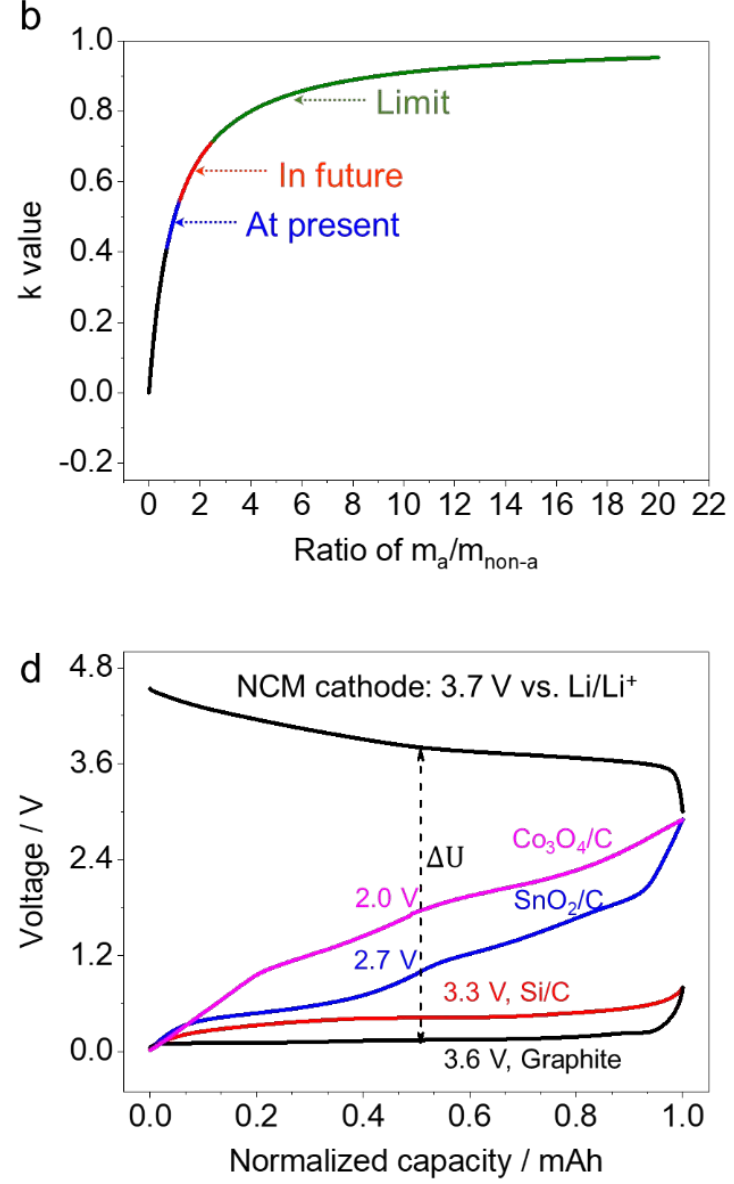

Figure 2. Factors used in our model and their impact on LIB performance: (a) E versus $k$ and $\Delta \mathrm{U}$, (b) k versus the ratio $\frac{\mathrm{m}_{\mathrm{a}}}{\mathrm{m}_{\mathrm{non}-\mathrm{a}}}$, and (c) $\mathrm{E}$ versus $\Delta \mathrm{U}$ and $\mathrm{C}_{\mathrm{n}}$. (d) $\Delta \mathrm{U}$ of a battery using NCM cathode with different anodes. 


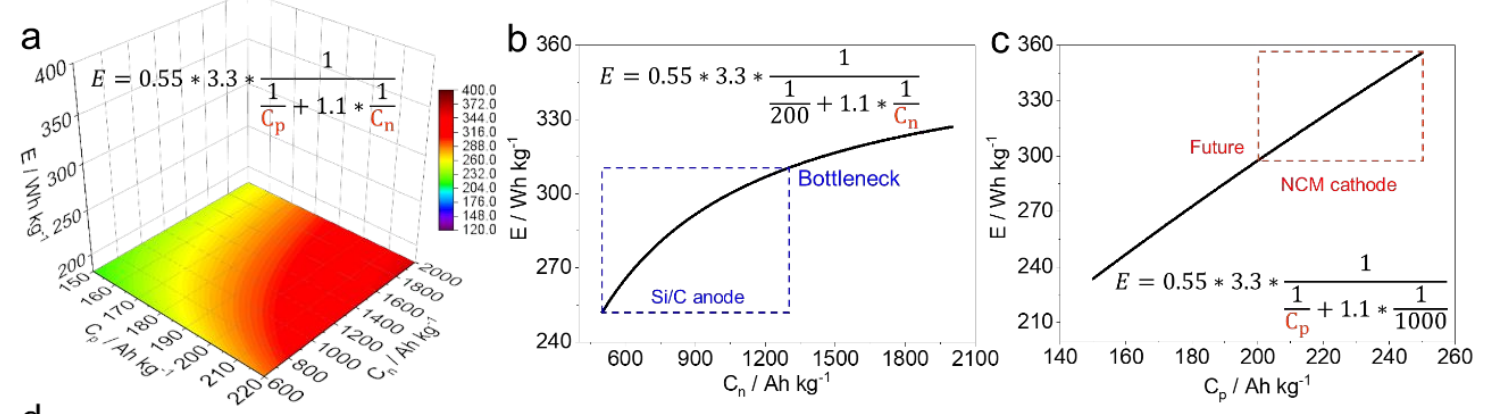

d

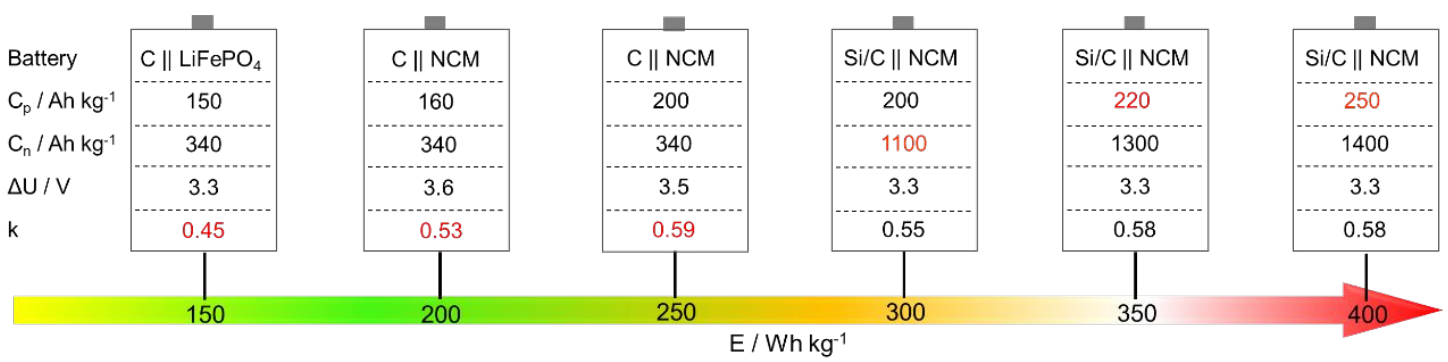

Figure 3. Impact of electrode capacity on the energy density of LIBs. The relationship between energy density (E) and (a) $C_{n}$ and $C_{p}$, (b) $C_{n}$, where $C_{p}$ is kept constant as $200 \mathrm{Ah} \mathrm{kg}^{-}$ 1, and (c) $\mathrm{C}_{\mathrm{p}}$, where $\mathrm{C}_{\mathrm{n}}$ is kept constant at $1000 \mathrm{Ah} \mathrm{kg}^{-1}$. (d) Our model prediction for achievable LIB energy density using various parameters. An energy density from $150 \mathrm{Wh} \mathrm{kg}^{-1}$ to $400 \mathrm{Wh}$ $\mathrm{kg}^{-1}$ can be achieved. 
a
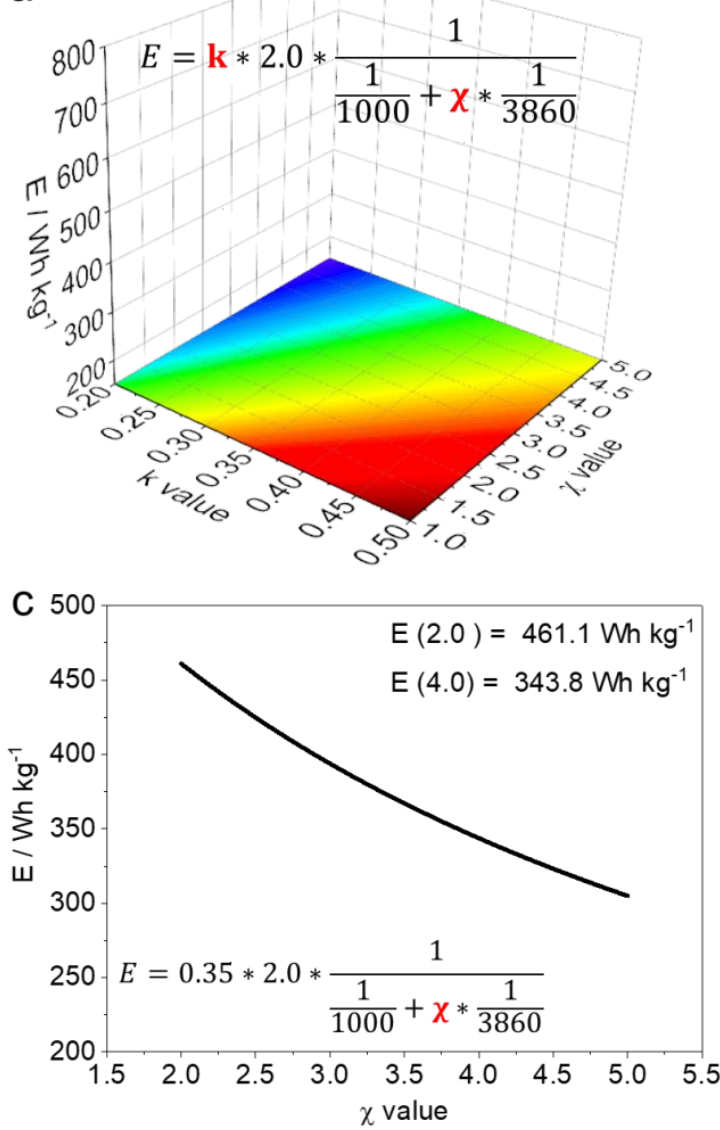

b
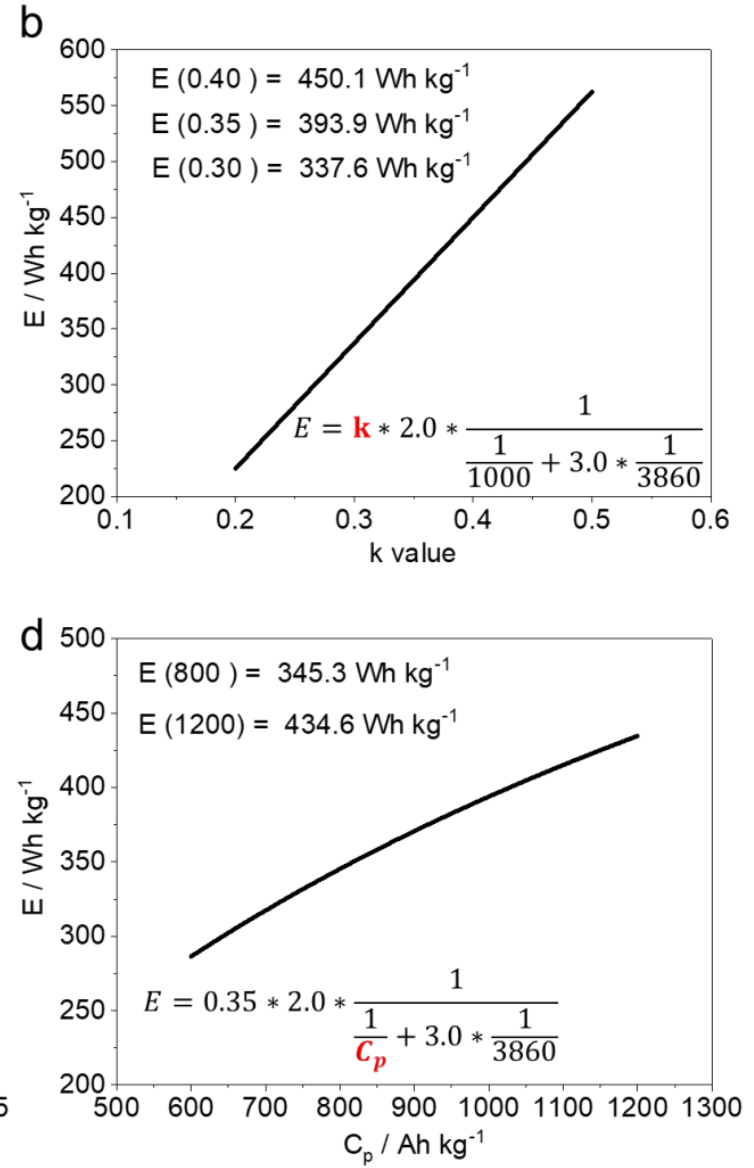

Figure 4. Application of the proposed model in Li-S battery. The relationship between energy density (E) and (a) $k$ and $\chi$ where $\Delta \mathrm{U}, \mathrm{C}_{\mathrm{p}}$, and $\mathrm{C}_{\mathrm{n}}$ are kept constant at $2.0 \mathrm{~V}, 1000 \mathrm{Ah}$ $\mathrm{kg}^{-1}$, and $3860 \mathrm{Ah} \mathrm{kg}^{-1}$, respectively. The relationship between E and (b) $\mathrm{k}$, (c) $\chi$, (d) $\mathrm{C}_{\mathrm{p}}$. 
a
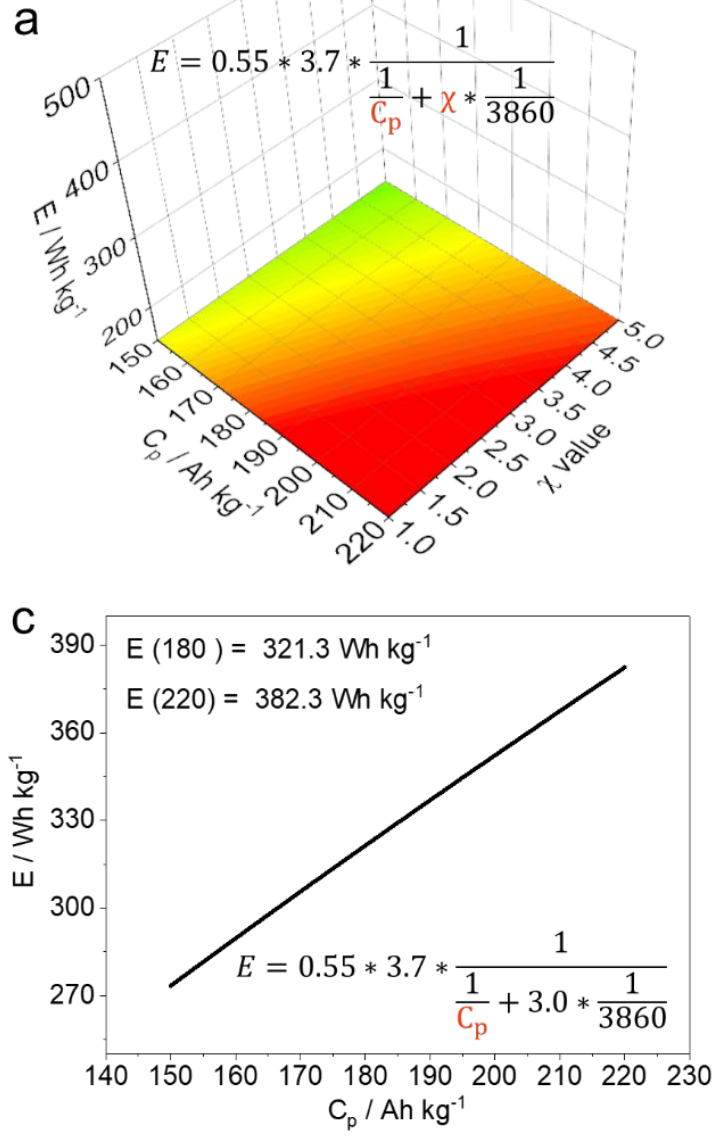
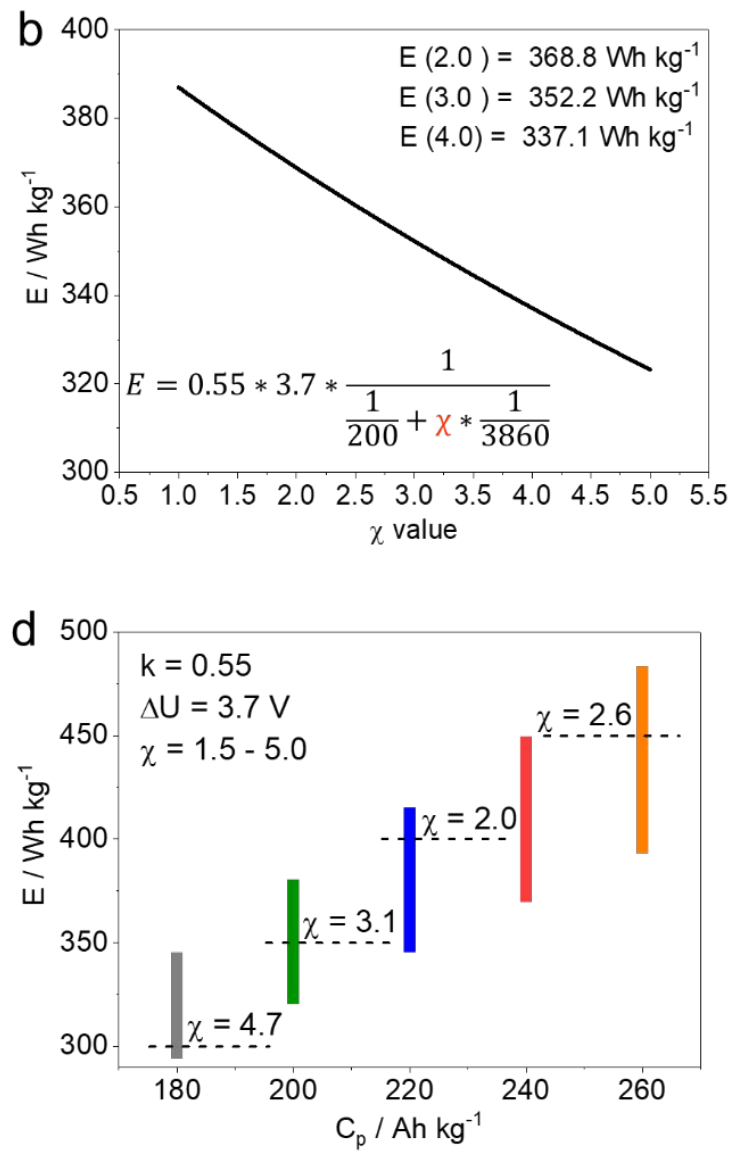

Figure 5. Application of the proposed model in Li-metal battery. The relationship between energy density (E) and: (a) $C_{p}$ and $\chi$, where the $\mathrm{k}, \Delta \mathrm{U}$, and $\mathrm{C}_{\mathrm{n}}$ are kept constant as $0.55,3.7 \mathrm{~V}$, and $3860 \mathrm{Ah} \mathrm{kg}^{-1}$, respectively; (b) $\chi$ and (c) $\mathrm{C}_{\mathrm{p}}$. (d) Strategy for designing Li $\|$ NCM battery with energy density ranging from $300 \mathrm{Wh} \mathrm{kg}^{-1}$ to $500 \mathrm{Wh} \mathrm{kg}^{-1}$ based on our model. 

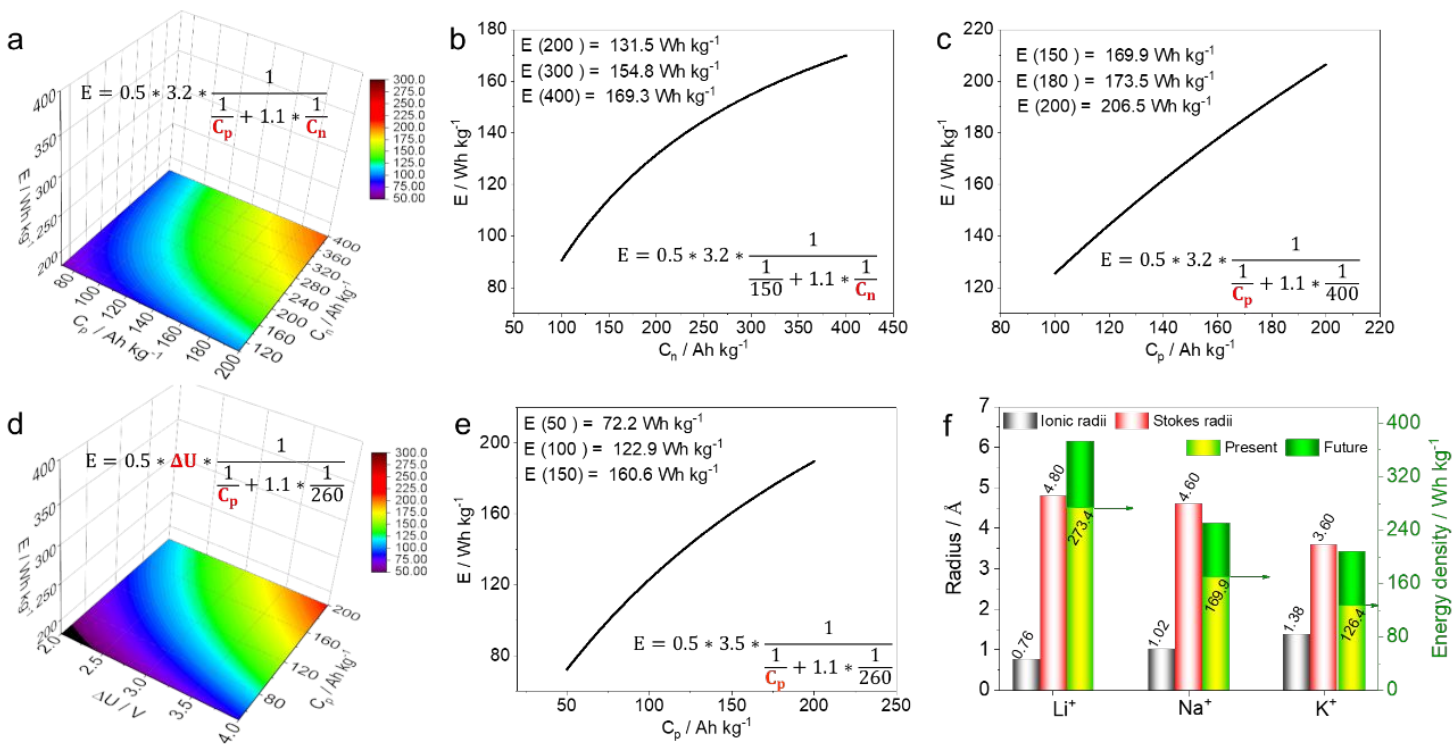

Figure 6. Application of the proposed model in NIBs and KIBs. The relationship between E (NIBs) and: (a) $C_{p}$ and $C_{n}$, (b) $C_{n}$ and (c) $C_{p}$, where the $k, \Delta U$, and $\chi_{\varepsilon_{\mathrm{p}}}^{\frac{\varepsilon_{n}}{2}}$ are kept constant as 0.5, 3.2 V, and 1.1, respectively; The relationship between $\mathrm{E}$ (KIBs) and: (d) $\Delta \mathrm{U}$ and $\mathrm{C}_{\mathrm{p}}$, (e) $\mathrm{C}_{p}$, where the $\mathrm{k}, \mathrm{C}_{\mathrm{n}}$, and $\chi_{\varepsilon_{\mathrm{p}}}^{\varepsilon_{\mathrm{n}}}$ are kept constant as $0.5,260 \mathrm{Ah} \mathrm{kg}^{-1}$, and 1.1, respectively. (f) Comparative ionic radii and Stokes radii of metal ions in PC solvent and the energy densities in current LIBs, NIBs, and KIBs. 


\title{
Supporting Information
}

The Supporting Information is available free of charge on the ACS Publications website at DOI: XXXX

Figure S1-S4 showing the dependence of energy density (E) on the k value under two different $\Delta \mathrm{U}$ values; dependence of $\mathrm{E}$ on $\mathrm{k}$ value in $\mathrm{C} \| \mathrm{LiFePO}_{4}$ battery, $\mathrm{C}_{\mathrm{n}}$ value in $\mathrm{Si} / \mathrm{C}$ || $\mathrm{LiFePO}_{4}$ battery, and $\mathrm{k}$ value in $\mathrm{C} \| \mathrm{NCM} 811$ battery; variation of $\mathrm{E}$ value with anode capacity $\left(\mathrm{C}_{\mathrm{n}}\right)$ and $\Delta \mathrm{U}$ value in a hypothetical high voltage battery; strategy and parameters for designing the Li-S battery with energy densities ranging from $300 \mathrm{Wh} \mathrm{kg}^{-1}$ to $500 \mathrm{Wh}$ $\mathrm{kg}^{-1}$. Tables S1-S3 showing the estimated energy density of LIBs using the NCM811 cathode combined with various anodes; electrode materials commonly used in K-ion battery; estimated energy density of KIBs calculated with $\mathrm{k}=0.5$ and $\chi_{\varepsilon_{\mathrm{p}}}^{\varepsilon_{\mathrm{n}}}=1.1$ (PDF).

\author{
AUTHOR INFORMATION \\ Corresponding Author \\ *E-mail: husam.alshareef@kaust.edu.sa (H. N. Alshareef); \\ *E-mail: yksun@,hanyang.ac.kr (Y.K. Sun); \\ *E-mail:jun.ming@eciac.ac.cn (J. Ming).
}

\section{Author Contributions}

The manuscript was written through the contributions of all authors. All authors have given approval to the final version of the manuscript. $\dagger \mathrm{Y}$. Wu, L. Xie, and H. Ming contributed equally.

\section{ACKNOWLEDGMENT}


This work is supported by the National Natural Science Foundation of China (21978281, 21703285, 21975250) and the National Key R\&D Program of China (SQ2017YFGH001474). The authors also thank the Independent Research Project of the State Key Laboratory of Rare Earth Resources Utilization (110005R086), Changchun Institute of Applied Chemistry, Chinese Academy of Sciences. The research was also supported by King Abdullah University of Science and Technology (KAUST) and Hanyang University. The authors also acknowledge fruitful discussions with the research scientists at Huzhou Kunlun Power Battery Materials Co., LTD.

\section{References}

(1) Cano, Z. P.; Banham, D.; Ye, S.; Hintennach, A.; Lu, J.; Fowler, M.; Chen, Z., Batteries and Fuel Cells for Emerging Electric Vehicle Markets. Nat. Energy 2018, 3, 279-289.

(2) Sun, Y. K., High-Capacity Layered Cathodes for Next-Generation Electric Vehicles. $A C S$ Energy Lett. 2019, 4, 1042-1044.

(3) Armand, M.; Tarascon, J. M., Building Better Batteries. Nature 2008, 451, 652.

(4) Wu, Y.; Ming, H.; Li, M.; Zhang, J.; Wahyudi, W.; Xie, L.; He, X.; Wang, J.; Wu, Y.; Ming, J., New Organic Complex for Lithium Layered Oxide Modification: Ultrathin Coating, High-Voltage, and Safety Performances. ACS Energy Lett. 2019, 4, 656-665.

(5) Kim, J. H.; Kim, S. J.; Yuk, T.; Kim, J.; Yoon, C. S.; Sun, Y. K., Variation of Electronic Conductivity within Secondary Particles Revealing a Capacity-Fading Mechanism of Layered Ni-Rich Cathode. ACS Energy Lett. 2018, 3, 3002-3007.

(6) Wu, Y. Q.; Xie, L. Q.; He, X. M.; Zhuo, L. H.; Wang, L. M.; Ming, J., Electrochemical Activation, Voltage Decay and Hysteresis of Li-rich Layered Cathode Probed by Various Cobalt Content. Electrochim. Acta 2018, 265, 115-120. 
(7) Zhang, J. N.; Li, Q.; Ouyang, C.; Yu, X.; Ge, M.; Huang, X.; Hu, E.; Ma, C.; Li, S.; Xiao, R.; Yang, W.; Chu, Y.; Liu, Y.; Yu, H.; Yang, X. Q.; Huang, X.; Chen, L.; Li, H., Trace Doping of Multiple Elements Enables Stable Battery Cycling of $\mathrm{LiCoO}_{2}$ at $4.6 \mathrm{~V}$. Nat. Energy 2019, 4, 594-603.

(8) Bruce, P. G.; Freunberger, S. A.; Hardwick, L. J.; Tarascon, J. M., Li-O ${ }_{2}$ and Li-S Batteries with High Energy Storage. Nat. Mater. 2012, 11, 19.

(9) Wahyudi, W.; Cao, Z.; Kumar, P.; Li, M.; Wu, Y.; Hedhili, M. N.; Anthopoulos, T. D.; Cavallo, L.; Li, L. J.; Ming, J., Phase Inversion Strategy to Flexible Freestanding Electrode: Critical Coupling of Binders and Electrolytes for High Performance Li-S Battery. Adv. Funct. Mater. 2018, 28, 1802244.

(10) Fu, K. K.; Gong, Y.; Liu, B.; Zhu, Y.; Xu, S.; Yao, Y.; Luo, W.; Wang, C.; Lacey, S. D.; Dai, J., Toward Garnet Electrolyte-based Li Metal Batteries: An Ultrathin, Highly Effective, Artificial Solid-State Electrolyte/Metallic Li Interface. Sci. Adv. 2017, 3, e1601659.

(11) Ming, J.; Cao, Z.; Wahyudi, W.; Li, M.; Kumar, P.; Wu, Y.; Hwang, J. Y.; Hedhili, M. N.; Cavallo, L.; Sun, Y. K.; Li, L. J., New Insights on Graphite Anode Stability in Rechargeable Batteries: Li Ion Coordination Structures Prevail over Solid Electrolyte Interphases. ACS Energy Lett. 2018, 3, 335-340.

(12) Xue, H. J.; Na, Z. L.; Wu, Y. Q.; Wang, X. X.; Li, Q.; Liang, F.; Yin, D. M.; Wang, L. M.; Ming, J., Unique $\mathrm{Co}_{3} \mathrm{O}_{4} / \mathrm{Nitrogen-doped} \mathrm{Carbon} \mathrm{Nanospheres} \mathrm{Derived} \mathrm{from} \mathrm{Metal-}$ Organic Framework: Insight into their Superior Lithium Storage Capabilities and Electrochemical Features in High-Voltage Batteries. J. Mater. Chem. A 2018, 6, 1246612474. 
(13) Ming, J.; Cao, Z.; Li, Q.; Wahyudi, W.; Wang, W.; Cavallo, L.; Park, K. J.; Sun, Y. K.; Alshareef, H. N., Molecular-Scale Interfacial Model for Predicting Electrode Performance in Rechargeable Batteries. ACS Energy Lett. 2019, 4, 1584-1593.

(14) Zhang, J.; Zhou, L.; Sun, Q.; Ming, H.; Sun, L.; Wang, C.; Wu, Y.; Guan, K.; Wang, L.; Ming, J., Metal-Organic Coordination Strategy for Obtaining Metal-Decorated Mo-Based Complexes: Multi-dimensional Structural Evolution and High-Rate Lithium-Ion Battery Applications. Chem-Eur. J. 2019, 25, 8813-8819.

(15) Zhuo, L. H.; Wu, Y. Q.; Wang, L. Y.; Ming, J.; Yu, Y. C.; Zhang, X. B.; Zhao, F. Y., $\mathrm{CO}_{2}$-expanded Ethanol Chemical Synthesis of a $\mathrm{Fe}_{3} \mathrm{O}_{4} @$ Graphene Composite and Its Good Electrochemical Properties as Anode Material for Li-Ion Batteries. J. Mater. Chem. A 2013, 1, 3954-3960.

(16) Sun, Q. J.; Zhou, L.; Sun, L. S.; Wang, C. L.; Wu, Y. Q.; Wang, X. X.; Wang, L. M.; Ming, J., Bioinspired Architectures and Heteroatom Doping To Construct Metal-OxideBased Anode for High-Performance Lithium-Ion Batteries. Chem-Eur. J. 2018, 24, 1690216909.

(17) Ming, H.; Qiu, J.; Zhang, S.; Li, M.; Zhu, X.; Wang, L.; Ming, J., Constructing Dense $\mathrm{SiO}_{\mathrm{x}} @$ Carbon Nanotubes versus Spinel Cathode for Advanced High-Energy Lithium-Ion Batteries. ChemElectroChem 2017, 4, 1165-1171.

(18) Liang, B.; Liu, Y.; Xu, Y., Silicon-based Materials as High Capacity Anodes for next Generation Lithium Ion Batteries. J. Power Sources 2014, 267, 469-490.

(19) Song, M. S.; Chang, G.; Jung, D. W.; Kwon, M. S.; Li, P.; Ku, J. H.; Choi, J. M.; Zhang, K.; Yi, G. R.; Cui, Y.; Park, J. H., Strategy for Boosting Li-Ion Current in Silicon Nanoparticles. ACS Energy Lett. 2018, 3, 2252-2258. 
(20) Yun, Q.; He, Y. B.; Lv, W.; Zhao, Y.; Li, B.; Kang, F.; Yang, Q. H., Chemical Dealloying Derived 3D Porous Current Collector for Li Metal Anodes. Adv. Mater. 2016, 28, 69326939.

(21) Fan, X.; Chen, L.; Borodin, O.; Ji, X.; Chen, J.; Hou, S.; Deng, T.; Zheng, J.; Yang, C.; Liou, S. C., Non-Flammable Electrolyte Enables Li-Metal Batteries with Aggressive Cathode Chemistries. Nat. Nanotech. 2018, 13, 715.

(22) Suo, L.; Xue, W.; Gobet, M.; Greenbaum, S. G.; Wang, C.; Chen, Y.; Yang, W.; Li, Y.; Li, J., Fluorine-Donating Electrolytes Enable Highly Reversible 5 V-Class Li Metal Batteries. Proc. Nat. Acad. Sci. USA 2018, 115, 1156-1161.

(23) Sathiya, M.; Abakumov, A. M.; Foix, D.; Rousse, G.; Ramesha, K.; Saubanère, M.; Doublet, M.; Vezin, H.; Laisa, C.; Prakash, A., Origin of Voltage Decay in High-Capacity Layered Oxide Electrodes. Nat. Mater. 2015, 14, 230.

(24) Patoux, S.; Daniel, L.; Bourbon, C.; Lignier, H.; Pagano, C.; Le Cras, F.; Jouanneau, S.; Martinet, S., High Voltage Spinel Oxides for Li-Ion Batteries: From the Material Research to the Application. J. Power Sources 2009, 189, 344-352.

(25) Kim, U. H.; Kuo, L. Y.; Kaghazchi, P.; Yoon, C. S.; Sun, Y. K., Quaternary Layered NiRich NCMA Cathode for Lithium-Ion Batteries. ACS Energy Lett. 2019, 4, 576-582.

(26)Li, Y.; Lu, J., Metal-Air Batteries: Will They Be the Future Electrochemical Energy Storage Device Of Choice? ACS Energy Lett. 2017, 2, 1370-1377.

(27) Ming, J.; Guo, J.; Xia, C.; Wang, W.; Alshareef, H. N., Zinc-ion batteries: Materials, mechanisms, and applications. Mater. Sci. Engin. R: Rep. 2019, 135, 58-84.

(28) Radin, M. D.; Hy, S.; Sina, M.; Fang, C.; Liu, H.; Vinckeviciute, J.; Zhang, M.; Whittingham, M. S.; Meng, Y. S.; Van der Ven, A., Narrowing the Gap between Theoretical and Practical Capacities in Li-Ion Layered Oxide Cathode Materials. $A d v$. Energy Mater. 2017, 7, 1602888. 
(29) Patil, A.; Patil, V.; Shin, D. W.; Choi, J. W.; Paik, D. S.; Yoon, S. J., Issue and Challenges Facing Rechargeable Thin Film Lithium Batteries. Mater. Res. Bull. 2008, 43, 1913-1942.

(30) Park, S. H.; King, P. J.; Tian, R.; Boland, C. S.; Coelho, J.; Zhang, C.; McBean, P.; McEvoy, N.; Kremer, M. P.; Daly, D.; Coleman, J. N.; Nicolosi, V., High Areal Capacity Battery Electrodes Enabled by Segregated Nanotube Networks. Nat. Energy 2019, 4, 560567.

(31) Huang, X.; Ke, S.; Lv, H.; Liu, Y., A Dynamic Capacity Fading Model with Thermal Evolution Considering Variable Electrode Thickness for Lithium-Ion Batteries. Ionics 2018, 24, 3439-3450.

(32) Lee, S. G.; Jeon, D. H.; Kim, B. M.; Kang, J. H.; Kim, C. J., Lattice Boltzmann Simulation for Electrolyte Transport In Porous Electrode of Lithium Ion Batteries. J. Electrochem. Soc. 2013, 160, H258-H265.

(33) Zhou, L.; Zhang, J.; Wu, Y.; Wang, W.; Ming, H.; Sun, Q.; Wang, L.; Ming, J.; Alshareef, H. N., Understanding Ostwald Ripening and Surface Charging Effects in Solvothermally-Prepared Metal Oxide-Carbon Anodes for High Performance Rechargeable Batteries. Adv. Energy Mater. 2019, 9, 1902194.

(34) Zhou, L.; Cheng, Y.; Sun, Q.; Sun, L.; Wang, C.; Wang, X.; Yin, D.; Wang, L.; Ming, J., High Alkaline Ion Storage Capacity of Hollow Interwoven Structured $\mathrm{Sb} / \mathrm{TiO}_{2}$ Particles: the Galvanic Replacement Formation Mechanism and Volumetric Buffer Effect. Chem. Commun. 2018, 54, 4049-4052.

(35) Ming, J.; Park, J. B.; Sun, Y. K., Encapsulation of Metal Oxide Nanocrystals into Porous Carbon with Ultrahigh Performances in Lithium-Ion Battery. ACS Appl. Mater. Interfaces 2013, 5, 2133-2136.

(36) Thackeray, M.; Johnson, P.; De Picciotto, L.; Bruce, P.; Goodenough, J., Electrochemical extraction of lithium from $\mathrm{LiMn}_{2} \mathrm{O}_{4}$. Mater. Res. Bull. 1984, 19, 179-187. 
(37) Kim, J. H.; Myung, S. T.; Yoon, C. S.; Kang, S.; Sun, Y. K., Comparative Study of $\mathrm{LiNi}_{0.5} \mathrm{Mn}_{1.5} \mathrm{O}_{4-\delta}$ and $\mathrm{LiNi}_{0.5} \mathrm{Mn}_{1.5} \mathrm{O}_{4}$ Cathodes Having Two Crystallographic Structures: fd $5 \mathrm{~m}$ and P4332. Chem. Mater. 2004, 16, 906-914.

(38) Seong, W. M.; Yoon, K.; Lee, M. H.; Jung, S. K.; Kang, K., Unveiling the Intrinsic Cycle Reversibility of a $\mathrm{LiCoO}_{2}$ Electrode at $4.8 \mathrm{~V}$ Cutoff Voltage through Subtractive Surface Modification for Lithium-Ion Batteries. Nano Lett. 2018, 19, 29-37.

(39) Ming, H.; Ming, J.; Oh, S. M.; Tian, S.; Zhou, Q.; Huang, H.; Sun, Y. K.; Zheng, J., Surfactant-Assisted Synthesis of $\mathrm{Fe}_{2} \mathrm{O}_{3}$ Nanoparticles and F-doped Carbon Modification toward An Improved $\mathrm{Fe}_{3} \mathrm{O}_{4} @ \mathrm{CF}_{\mathrm{x}} / \mathrm{LiNi}_{0.5} \mathrm{Mn}_{1.5} \mathrm{O}_{4}$ Battery. ACS Appl. Mater. Interfaces 2014, 6, 15499-509.

(40) Zhuo, L. H.; Wu, Y. Q.; Ming, J.; Wang, L. Y.; Yu, Y. C.; Zhang, X. B.; Zhao, F. Y., Facile Synthesis of $\mathrm{a} \mathrm{Co}_{3} \mathrm{O}_{4}$-Carbon Nanotube Composite and Its Superior Performance as an Anode Material for Li-Ion Batteries. J. Mater. Chem. A 2013, 1, 1141-1147.

(41) An, S. J.; Li, J.; Daniel, C.; Mohanty, D.; Nagpure, S.; Wood III, D. L., The State of Understanding of the lithium-Ion-Battery Graphite Solid Electrolyte Interphase (SEI) and Its Relationship to Formation Cycling. Carbon 2016, 105, 52-76.

(42) Tian, H.; Tan, X.; Xin, F.; Wang, C.; Han, W., Micro-Sized Nano-Porous Si/C Anodes for Lithium Ion Batteries. Nano Energy 2015, 11, 490-499.

(43) Wu, Y. Q.; Ming, J.; Zhuo, L. H.; Yu, Y. C.; Zhao, F. Y., Simultaneous surface coating and chemical activation of the Li-rich solid solution lithium rechargeable cathode and its improved performance. Electrochim. Acta 2013, 113, 54-62.

(44) Yao, Z.; Xia, X.; Xie, D.; Wang, Y.; Zhou, C.; Liu, S.; Deng, S.; Wang, X.; Tu, J., Enhancing Ultrafast Lithium Ion Storage of $\mathrm{Li}_{4} \mathrm{Ti}_{5} \mathrm{O}_{12}$ by Tailored $\mathrm{TiC} / \mathrm{C}$ Core/Shell Skeleton Plus Nitrogen Doping. Adv. Funct. Mater. 2018, 28, 1802756. 
(45) Pang, Q.; Liang, X.; Kwok, C. Y.; Nazar, L. F., Advances in Lithium-Sulfur Batteries based on Multifunctional Cathodes and Electrolytes. Nat. Energy 2016, 1, 16132.

(46) Agostini, M.; Hwang, J. Y.; Kim, H. M.; Bruni, P.; Brutti, S.; Croce, F.; Matic, A.; Sun, Y. K., Minimizing the Electrolyte Volume in Li-S Batteries: A Step Forward to High Gravimetric Energy Density. Adv. Energy Mater. 2018, 8, 1801560.

(47) Ming, J.; Li, M. L.; Kumar, P.; Li, L. J., Multilayer Approach for Advanced Hybrid Lithium Battery. ACS Nano 2016, 10, 6037-6044.

(48) Ming, J.; Li, M.; Kumar, P.; Lu, A. Y.; Wahyudi, W.; Li, L. J., Redox Species-Based Electrolytes for Advanced Rechargeable Lithium Ion Batteries. ACS Energy Lett. 2016, 1, $529-534$.

(49) Li, M.; Wahyudi, W.; Kumar, P.; Wu, F.; Yang, X.; Li, H.; Li, L. J.; Ming, J., Scalable Approach To Construct Free-Standing and Flexible Carbon Networks for Lithium-Sulfur Battery. ACS Appl. Mater. Interfaces 2017, 9, 8047-8054.

(50) Wang, W.; Cao, Z.; Elia, G. A.; Wu, Y.; Wahyudi, W.; Abou-Hamad, E.; Emwas, A. H.; Cavallo, L.; Li, L. J.; Ming, J., Recognizing the Mechanism of Sulfurized Polyacrylonitrile Cathode Materials for Li-S Batteries and beyond in Al-S Batteries. ACS Energy Lett. 2018, 3, 2899-2907.

(51) Li, H., Practical Evaluation of Li-Ion Batteries. Joule 2019, 3, 911-914.

(52) Kubota, K.; Komaba, S., Practical Issues and Future Perspective for Na-Ion Batteries. $J$. Electrochem. Soc. 2015, 162, A2538-A2550.

(53) Han, M. H.; Gonzalo, E.; Singh, G.; Rojo, T., A Comprehensive Review of Sodium Layered Oxides: Powerful Cathodes for Na-Ion Batteries. Energy Environ. Sci. 2015, 8, 81-102. 
(54) Meng, Q.; Lu, Y.; Ding, F.; Zhang, Q.; Chen, L.; Hu, Y.-S., Tuning the Closed Pore Structure of Hard Carbons with the Highest Na Storage Capacity. ACS Energy Lett. 2019, 4, 2608-2612.

(55)Hu, Y.-S.; Lu, Y., 2019 Nobel Prize for the Li-Ion Batteries and New Opportunities and Challenges in Na-Ion Batteries. ACS Energy Lett. 2019, 4, 2689-2690

(56) Hosaka, T.; Kubota, K.; Kojima, H.; Komaba, S., Highly Concentrated Electrolyte Solutions for 4 V Class Potassium-Ion Batteries. Chem. Commun. 2018, 54, 8387-8390.

(57) Clites, M.; Hart, J. L.; Taheri, M. L.; Pomerantseva, E., Chemically Preintercalated Bilayered $\mathrm{K}_{\mathrm{x}} \mathrm{V}_{2} \mathrm{O}_{5} \cdot \mathrm{nH}_{2} \mathrm{O}$ Nanobelts as a High-Performing Cathode Material for K-Ion Batteries. ACS Energy Lett. 2018, 3, 562-567.

(58) Masese, T.; Yoshii, K.; Yamaguchi, Y.; Okumura, T.; Huang, Z. D.; Kato, M.; Kubota, K.; Furutani, J.; Orikasa, Y.; Senoh, H.; Sakaebe, H.; Shikano, M., Rechargeable Potassium-Ion Batteries with Honeycomb-Layered Tellurates as High Voltage Cathodes and Fast Potassium-Ion Conductors. Nat. Commun. 2018, 9, 3823.

(59) Hwang, J. Y.; Kim, H. M.; Yoon, C. S.; Sun, Y. K., Toward High-Safety PotassiumSulfur Batteries Using a Potassium Polysulfide Catholyte and Metal-Free Anode. ACS Energy Lett. 2018, 3, 540-541.

(60) Hosaka, T.; Kubota, K.; Hameed, A. S.; Komaba, S., Research Development on K-Ion Batteries. Chem. Rev. 2020, DOI.org/10.1021/acs.chemrev.9b00463.

(61)Zhou, L.; Cao, Z.; Wandi W.; Zhang, J.; Hwang, J. Y.; Cheng, Y.; Wang, L.; Cavallo, L. Anthopoulos, T. D., Sun, Y. K.; Alshareef, H.N.; Ming, J. Electrolyte Engineering Enables High Stability and Capacity Alloying Anodes for Sodium and Potassium Ion Batteries, ACS Energy Lett., 2020, DOI.org/10.1021/acsenergylett.0c00148. 